\title{
Stupidity as Normal
}

ISSN: 2637-8078

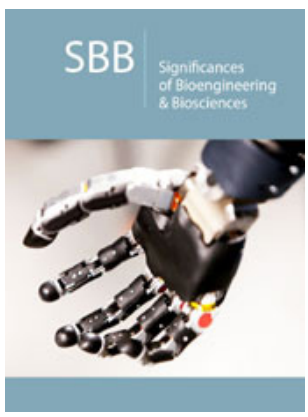

*Corresponding author: James F Welles, P O Box 17, East Marion, New York, USA, Email: jwelles103@aol.com

Submission:

Published: 覀September 24, 2019

Volume 3 - Issue 4

How to cite this article: James F Welles. Stupidity as Normal. Significances Bioeng Biosci.3(4). SBB.000570.2019.

DOI: 10.31031/SBB.2019.03.000570

Copyright@ James F Welles, This article is distributed under the terms of the Creative Commons Attribution 4.0 International License, which permits unrestricted use and redistribution provided that the original author and source are credited.
James F Welles*

East Marion, New York, USA

\section{Introduction}

When considering "Stupidity" in such works, it is important to distinguish between the word and the phenomenon. The word stems from the Latin stupere, meaning dumb or astounded and is related to "Stupor". It may be used to designate a mentality which is informed, deliberate and maladaptive but nevertheless normal. Usually, the term "Stupidity" is used like an extreme swear word-a put-down for those deemed intellectually inferior although this tactic may reveal more about the attitude of the user than the cognitive abilities of the designatee(s). On the other hand, as a disparaging term for members of an outgroup, the word "Stupidity" often indicates little more than a biased evaluation of behavior. If we do " $\mathrm{X}$ " it is smart or necessary; if they do " $\mathrm{X}$ " it is stupid [1].

For example, when contemplating President Reagan's "Star Wars" defense system, freespending Democrats suddenly became fiscal conservatives, [2] so spending on that program was deemed stupid. As the same act may be interpreted as both stupid and reasonable (or brilliant), we do indeed live in a perceptual world of " $\mathrm{A}$ " and "Not A": that is, a statement may be true and false at the same time e.g., "History is about people" is superficially true, but it is also about geography, economics, psychology, etc,. [3]. Further, changes through time may alter prejudiced evaluations, so the label "Stupid" may express nothing more than a temporal estimate made according to arbitrary standards subjectively applied to perceived conditions. Thus, stupidity was invoked as the best explanation for the deaths of thousands of young men during WWII for no good reason over [3].

"Meaningless" bridges referring to those at Nijmegen (the "Bridge Too Far") and Remagen [4]. This analysis conveniently omits the fact that, at their moments in time, these bridges were potentially if not indeed tremendously meaningful. As a phenomenon, stupidity is most often a limited and limiting experience pattern [5] (or, conversely, one that is over-expanded and overextending). In either case, it is caused by a belief blocking the formation or function of one more relevant to given conditions. Something in the environment is not matched in the cognitive world because the existing schema is too emotionally entrenched to permit an accurate appraisal of incoming data. First and foremost, the mind is an instrument for beliefnot for knowing, learning or problem solving but for believing [6] and it works to thwart intelligence (i.e., the ability to foresee consequences of one's actions and the capacity to restructure one's schema according to experience) no matter how upsetting that experience of profitable learning may be.

There are really two dependent aspects to schematic stupidity: one is that a schema induces stupidity, and the other is that a schema is stupid. Almost every schema induces stupidity in that it is a belief system which inhibits the formation of improved beliefs, functional ideas and refined perceptions. Oddly enough, even a schema of "Open-mindedness" can be stupid if it inhibits the development of more accurate perceptions and an appreciation of the better ideas among those available. This is the chief drawback of the liberal schema, which tends to treat all forms of behavior, cognitions, beliefs and everything else equally whether they are actually equally good or not. As for a schema being stupid, every one of them is by one standard or another, in that each is a compromise of the beliefs upon which a society is based, the ideas it promotes and the behavior it permits. 
An internally consistent schema may be repressively flat to the point of boredom for those who hold it while being maniacally disruptive to those around them. If a schema cannot motivate people to do anything more than just believe and exist, it and they may lose out to more inspiring belief systems of competing groups. At the other extreme, schemas which dominated and then died litter the intellectual byways of history. It is really this motivational dynamic of our social nature which makes our verbal schemas inherently maladaptive and us so chronically stupid.

\section{References}

1. Halpern D (2002) Sex, lies, and audiotapes: The Clinton-lewinsky scandal. In: Sternberg R (Ed.), Why smart people can be so stupid. Yale University Press, Connecticut, USA, p. 106.
2. Coulter A (2003) Treason. Crown Forum, New York, USA, p. 162.

3. Judt T (2012) Thinking the twentieth century. Penguin, New York, USA, p. 397.

4. Hanson VD (2004) If the dead could talk. Hoover Digest 4: 17-18.

5. Pitkin BW (1932) a short introduction to the history of human stupidity. Simon and Schuster, New York, USA, p. 129.

6. Shermer M (2011) The believing brain. Times books.

For possible submissions Click below: 